\title{
Pigeonpea Biological Seed Coating: Combined Inoculation of Biofertilizers and Bioprotectants
}

\author{
V. Jagadeesh ${ }^{1}$, P. Sujatha ${ }^{1 *}$, S. Triveni ${ }^{2}$, K. Keshavulu ${ }^{1}$ and K. Raghavendra ${ }^{3}$ \\ ${ }^{1}$ Department of Seed Science and Technology, PJTSAU, Rajendranagar, Hyderabad 30, \\ Telangana, India \\ ${ }^{2}$ Department of Agriculture Microbiology and Bio-energy, PJTSAU, Rajendranagar, \\ Hyderabad 30, Telangana, India \\ ${ }^{3}$ Centor India, Hyderabad, Telangana, India
}

*Corresponding author

\section{A B S T R A C T}

The present investigation is carried out to study the viability and shelf life of Rhizobium and Phosphorus Solubilizing Bacteria in the combined inoculations with either

\section{Keywords}

Combined inoculation, Biofertilizer,

Bioprotectant, Pigeonpea

Article Info

Accepted:

25 April 2018

Available Online:

10 June 2018
Trichoderma viride or Pseudomonas fluorescens on the biologically coated Pigeonpea seed. The effect of combined inoculation on the viability and shelf life of biofertilizers and seed quality parameters were studied at monthly intervals during storage period of six months. The results indicated that among adjuvants, seed inoculated with biofriendly polymer recorded more colony units and long shelf life than farmer practiced sugar syrup. At the end of six months storage period, both Rhizobium and Phosphorus Solubilizing Bacteria with biofriendly polymer recorded sufficient number of colony units on the surface of biologically coated pigeonpea seed. Both Rhizobium and PSB showed high colony counts with Trichoderma than with Pseudomonas and same trend was recorded throughout the storage period of six months. At the end of storage period, good seed germination and seedling vigour was recorded in the seeds that are co-inoculated with PSB and Pseudomonas than with Trichoderma and Rhizobium. This study reveals that the farmers can be supplied biologically coated seed in advance and the general practice of treating the seed a day prior to sowing can be avoided.

\section{Introduction}

Pigeonpea [Cajanus cajan (L.)] is an important staple food pulse crop rich in protein content of $22 \%$, which is almost three times that of cereals. Throughout the world pigeon pea is cultivated in an area of $6.23 \mathrm{Mha}$ with a production of $4.68 \mathrm{Mt}$ and productivity of $751 \mathrm{~kg} \mathrm{ha}^{-1}$ (India stat, 2014-2015). In India, pigeon pea is cultivated in an area of $3.90 \mathrm{mha}$ with a production of $3.17 \mathrm{Mt}$ and productivity of $813 \mathrm{~kg} \mathrm{ha}^{-1}$ (IIPR, 2014 and FAO, 2016). The main constraints in obtaining potential yield of the pigeon pea are incidence of diseases, insects and other physiological stresses in the field. Early stages of plant growth (4-6 week old plant) period are mostly susceptible which essentially affects yield. 
These diseases drastically influence the field emergence, seedling establishment and plant stand in the field finally leading to the reduction in the productivity and production.

Moreover, the seed performance can be enhanced by the way of application of fungicides, insecticides and other protecting agents on to the seed surface by means of coating to protect the seed from pathogens.

Even though seed treatment with biological agents is not new, the main constraint is that the seed treatment can only be done just before the sowing. Because of hectic field operations, mostly farmers are skipping this important process of seed inoculation which is leading to poor field stand in the pulses.

Keeping this in view, the present investigation is planned to find out the technology output for taking up of combined inoculation of biocontrol agents and biofertilizers well in advance of taking up of sowing i.e., at the time of seed processing and packaging stage only. This may provide an assurance to the farmer sown seed with good quality and seedling protection under field conditions.

This study is planned to investigate the effect of biofriendly polymer as an adjuvant against farmer practiced sugar syrup on the retention of viability and shelf life of various biological agents used for combined inoculation of pigeonpea seed. It is also planned to know the effect of combined inoculation on the pigeon seed quality and its storability.

\section{Materials and Methods}

The present investigation was out during Kharif, 2015 and Rabi, 2016 at Department of Seed Science and Technology and Department of Agricultural Microbiology and Bio-energy, College of Agriculture, PJTSAU, Rajendranagar, Hyderabad, Telangana.

\section{Materials}

Freshly harvested seeds of LRG - 41 variety of Pigeonpea were collected from Regional Agricultural Research Station, Lam, Guntur, Andhra Pradesh.

The seed possessed initial germination of 85 $\%$, electrical conductivity of seed leachates as $12.12 \mu \mathrm{mhos} / \mathrm{cm}$ and seed moisture content of $8.1 \%$.

Biological agents like Trichoderma viride, Pseudomonas fluorescens, Rhizobium spp and Phosphorous Solubilizing Bacteria were obtained from Agri Biotech Foundation (ABF), Rajendranagar, Hyderabad and Telangana. Bio friendly polymer was collected from Centor India, Secunderabad, Telangana.

\section{Methodology}

\section{Biological seed coating}

For biological seed coating, two different adjuvants like bio friendly polymer or sugar syrup were used @ $6 \mathrm{~g} \mathrm{~kg}^{-1}$ seed. Biological agents like Trichoderma viride, Pseudomonas fluorescens, Rhizobium and Phosphorous Solubilizing Bacteria were used @ $12 \mathrm{~g} \mathrm{~kg}^{-1}$ seed. Biological seed coating was done with combined inoculation of biofertilizers with biocontrol agents using biofriendly polymer. For each treatment, $600 \mathrm{~g}$ pigeon pea seed was weighed separately and placed into seed coating machine.

Biological coating material was prepared by weighing $3 \mathrm{~g}$ of adjuvant (either biofriendly polymer or sugar syrup) into a beaker and to that $3 \mathrm{~g}$ of distilled water was added and mixed thoroughly. To this diluted adjuvant, for combined inoculation of two biological agents $6 \mathrm{~g}$ of each organism (One biofertilizer and one biocontrol agent) was used for preparing slurry. Uniformly coated seed was 
removed from the coating machine and was shade dried for $2 \mathrm{hr}$. This treated seed was then made into 3 replications @ 200 g each and packed in zip lock polythene covers and kept for storage under ambient conditions for six months.

\section{Treatments}

T1: Seed + Trichoderma viride + Rhizobium + Biofriendly polymer

T2: Seed + Trichoderma viride + Rhizobium + Sugar syrup

T3: Seed + Pseudomonas fluorescens+ Rhizobium + Biofriendly polymer

T4: Seed + Pseudomonas fluorescens + Rhizobium + Sugar syrup

T5: Seed + Trichoderma viride + Phosphorus Solubilizing Bacteria (PSB) + Biofriendly polymer

T6: Seed + Trichoderma viride + Phosphorus Solubilizing Bacteria (PSB) + Sugar syrup

T7: Seed + Pseudomonas fluorescens+ Phosphorus Solubilizing Bacteria (PSB) + Biofriendly polymer

T8: Seed + Pseudomonas fluorescens+ Phosphorus Solubilizing Bacteria (PSB) + Sugar syrup

T9: Seed (Untreated Control)

Testing of Viability and Shelf-life of Biological Agents

\section{Preparation of Media}

Four different media were used for inoculation of four different microorganisms. They are as follows
Potato Dextrose Agar media for Trichoderma viride

Potato Dextrose Agar medium (Hi-Media) was used for the isolation of total fungi population from inoculated sample in Petri plates to take CFU counts. To prepare this media, $31.55 \mathrm{~g}$ of Potato Dextrose Agar was taken and dissolved in $1000 \mathrm{ml}$ of distilled water and sterilized in an autoclave at 15 psi $\left(121^{0} \mathrm{C}\right)$ for $15 \mathrm{~min}$. Sterilized Potato Dextrose agar was poured on to the sterilized petri plates $(20 \mathrm{ml}$ media per $90 \mathrm{~mm}$ diameter plate) and incubated in inverted position for $24 \mathrm{hr}$, after solidification

\section{Kings' B media for Pseudomonas fluorescens}

Kings' B medium was prepared by taking 31.3 $\mathrm{g}$ of Kings' $\mathrm{B}$ media and $15 \mathrm{~g}$ of agar powder in $1000 \mathrm{ml}$ of distilled water and sterilized in an autoclave at $15 \mathrm{psi}\left(121^{\circ} \mathrm{C}\right)$ for 15 min.Sterilized media was poured as a thin layer on to the sterilized petri plates $(20 \mathrm{ml}$ media per $90 \mathrm{~mm}$ diameter plate) and incubated for $24 \mathrm{hr}$, after solidification.

\section{Yeast Extract Mannitol Agar media} (YEMA) for Rhizobium spp

This medium was prepared by taking $31.83 \mathrm{~g}$ Yeast Extract Mannitol with Congo Red medium (Hi-Media) and dissolving in $1000 \mathrm{ml}$ of water and sterilized in an autoclave at 15 psi $\left(121^{0} \mathrm{C}\right)$ for $15 \mathrm{~min}$. Sterilized media was poured as a thin layer on to the sterilized petri plates (20 ml media per $90 \mathrm{~mm}$ diameter plate) and incubated for $24 \mathrm{hr}$, after solidification.

Pikovskaya's agar media for Phosphorus Solubilising Bacteria

This media was prepared by taking $31.13 \mathrm{~g}$ Pikovskaya's agar powder and dissolving in $1000 \mathrm{ml}$ of distilled water and sterilized in an 
autoclave at $15 \mathrm{psi}\left(121^{\circ} \mathrm{C}\right)$ for 15 min.Sterilized Pikovskaya's agar was poured as a thin layer on to the sterilized petri plates (20 ml media per $90 \mathrm{~mm}$ diameter plate) and incubated for $24 \mathrm{hr}$, after solidification. After incubation the Pikovskaya's plates were spot inoculated and incubated at $28 \pm 2^{0} \mathrm{C}$ for $4-5$ days. Formations of a clear zone around the colonies were considered as positive result for phosphate solubilisation.

\section{Sample Preparation}

To estimate the activity of biological organisms on coated seed and bio formulations, samples of $1 \mathrm{~g}$ were taken by using electronic weighing balance.

\section{Serial Dilution}

Serial of diluted blanks ( 7 or 8 ) were prepared by adding $9 \mathrm{ml}$ of saline water $(0.85 \% \mathrm{NaCl})$ into each blank (pre sterilized test tube). After preparation of dilution blanks, $1 \mathrm{~g}$ of test sample (formulation or biologically coated seed) was placed into the first blank and it was thoroughly homogenized with cyclo mixer for 30 seconds.

One ml of sample solution was taken from first blank and added to second blank, thoroughly homogenized with cyclo mixer for 30 seconds and again $1 \mathrm{ml}$ of sample solution from second blank was added to third blank. In this way, process of serial dilutions was continued upto $7^{\text {th }}$ blank.

\section{Plating Method}

For inoculation, diluted test sample from $4^{\text {th }}$ or $5^{\text {th }}$ serial dilution blanks were taken for effective counting of colony forming units of biological organisms. Diluted test sample of $0.1 \mathrm{ml}$ from $4^{\text {th }}$ or $5^{\text {th }}$ serial dilution blanks were inoculated on to the media of each petri plate in 3 replications. After inoculation petri plates containing testing sample of biological organisms are spread with the help of spreaders and master spreader.

\section{Incubation}

After inoculation, petri plates were kept for incubation in BOD incubator at maximum incubation temperature of $25^{\circ} \mathrm{C}$ for fungi and $37^{\circ} \mathrm{C}$ for bacteria for $2-5$ days for observing clear colony forming units on respective media petri plates.

\section{Enumeration of Microbial Colonies}

Colony forming units of Trichoderma, Pseudomonas, Rhizobium and Phosphorous Solubilizing Bacteria, were determined by serial dilution and plating on selective media as mentioned above. Replicates of the inoculated agar plates were incubated for 2 days at $37^{\circ} \mathrm{C}$ for Rhizobium, Pseudomonas and Phosphorous solubilizing bacteria and 5 days for fungi at $25^{\circ} \mathrm{C}$, after which the counts were taken with the help of colony counter.

Total number of colony forming units Total number of microbes $=$

Volume of the sample $\times$ dilution factor

\section{Testing of seed quality and storability of biologically coated seed of pigeon pea}

\section{Seed Germination (Percent)}

The laboratory test for germination was conducted as per the ISTA rules (ISTA, 2009) by adopting between paper method. Three replications of 100 seeds each were taken from each treatment and uniformly place on germination paper. The rolled towel was kept in the seed germinator and maintained a constant temperature of $25 \pm 0.5^{\circ} \mathrm{c}$ and 95 per cent relative humidity. Evaluation of normal seedlings, abnormal seedlings, fresh ungerminated seeds and dead seeds were done 
on sixth day. Germination percentage is expressed on the number of normal seedlings by following

Germination \% =

Number of normal seedlings

Total number of seeds planted

\section{Seedling length}

Ten normal seedlings were selected randomly per replication in each treatment on $6^{\text {th }}$ day of germination test. The root length was measured from the tip of the primary root to base of the hypocotyl with the help of a scale and the mean root length was expressed in centimeters.

Ten normal seedlings used for root length measurement, were also used for the measurement of shoot length.

The shoot length was measured from the tip of the primary leaf to the base of the hypocotyl and mean shoot length was expressed in centimeters.

\section{Seedling dry weight (g)}

Ten seedlings in each replication of germination test were oven dried in hot air oven at $80^{\circ} \pm 1^{0} \mathrm{C}$ for one day and dry weight per seedling was expressed in grams (g).

\section{Statistical Analysis}

The data recorded were analyzed statistically by adopting Completely Randomized Design (CRD), as described by Panse and Sukhatma (1985) and the standard error of difference was calculated at 5\% probability level to compare the mean difference among the treatments. The data recorded as percentage were transformed to the respective angular (arc sin) values before subjecting them to statistical analysis.

\section{Results and Discussion}

Effect of biofriendly polymer and biocontrol agents on the viability of biofertilizers in the combined inoculations on the biologically coated seed of pigeonpea

Rhizobium showed (Figure 1) high colony counts in its combined inoculation with Trichoderma $\left(16.8 \times 10^{5} \mathrm{cfu} \mathrm{g} \mathrm{seed}^{-1}\right)$ than

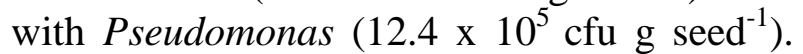
Statistically significant reduction was observed in the colony counts of Rhizobium in its combined inoculations with Pseudomonas compared to Trichoderma. But no significant change was observed in the colony counts of PSB in their combined inoculations either with Trichoderma or with Pseudomonas.

With regard to biocotrol agents, Trichoderma recorded a decrease in the colony units in its combined inoculations with PSB compared to Rhizobium. But Pseudomonas showed no significant change in the colony counts in its combined inoculations either with Rhizobium or with PSB (Figure 2).

Effect of adjuvants and biocontrol agents on the shelf life of biofertilizers in the combined inoculations on the biologically coated pigeonpea seed

Biofertilizers recorded numerically more colony counts and longer shelf life with biofriendly polymer and with Trichoderma compared to Pseudomonas.

Among adjuvants, seed inoculated with biofriendly polymer recorded more colony units than farmer practiced sugar syrup (Table1 and Plate 1).

At the end of six months storage period, Rhizobium recorded comparatively more number of colony units $\left(1.0 \times 10^{-5} \mathrm{cfu} \mathrm{g}^{-1}\right.$ seed) with biofriendly polymer. 
Immediately after biological coating on to the seed surface of pigeonpea, Rhizobium with biofriendly polymer (Table 1) recorded statistically high colony counts with Trichoderma (15.2 $\quad$ x $10^{-5} \quad \mathrm{cfu}^{\mathrm{g}^{-1}}$ seed) compared with Pseudomonas $\left(6.0 \times 10^{-5} \mathrm{cfu} \mathrm{g}^{-}\right.$ 1 seed) upto 3 months after inoculation. Thereafter, a gradual reduction in the colony units was observed upto six months. But there was sufficient number of counts were observed six months after inoculation on the surface of biologically coated pigeonpea seed (Figure 2). Like that of Rhizobium, Phosphorus Solubilizing Bacteria also recorded similar trend of shelf life with Trichoderma and biofriendly polymer throughout the storage period of six months (Table 2 and Figure 3).

Effect of biological seed coating with combined inoculation of biofertilizers and biocontrol agents on pigeonpea seed germination (\%) and germination parameters

With the advancement of storage period there was a gradual decrease in the seed germination. Drop down in the seed germination was observed to be less in the combined inoculation of biofertilizers with Pseudomonas (7\%) than with Trichoderma (12\%).

Among the biofertilizers, comparatively Phosphorus Solubilizing Bacteria recorded good seed quality and storability than Rhizobium (Figure 4 and 5).

In combined inoculations with Trichoderma viride (Figure 4), seeds inoculated with PSB showed significantly higher germination compared to Rhizobium. But this effect was non- significant after six months of inoculation. Similar trend was observed with Pseudomonas and PSB and the effect was significant even after 6 months of combined inoculation (Figure 5).
No significant effect was observed in germination parameters like seedling length $(\mathrm{cm})$ and seedling dry weight $(\mathrm{mg})$ (Figure 6, 7,8 and 9).

Effect of biological seed coating with combined inoculation of biofertilizers and biocontrol agents on pigeonpea seedling vigour and Electrical Conductivity

With the advancement of storage period there was a gradual decrease in the seedling vigour. Six months after storage, significantly high seedling vigour index-I (Figure $10 \& 11$ ) was observed with the combined inoculation of PSB with Pseudomonas (1178) than with Trichoderma (972).

High seedling vigour index-II (Figure 12 \& 13) was recorded in seeds with combined inoculation of PSB with Pseudomonas (69) than with Trichoderma and untreated control (65) at six months after storage.

Electrical conductivity of biologically coated pigeonpea seed was presented in the Figures 14 and 15. Irrespective of treatments, there was an increase in the electrical conductivity throughout the storage period of six months. Seeds inoculated with PSB showed significantly less electrical conductivity than Rhizobium and untreated control.

\section{Effect of biofriendly polymer and biocontrol agents on the viability and shelf life of biofertilizers in the combined inoculations on the biologically coated seed of pigeonpea}

Among adjuvants, seed inoculated with biofriendly polymer recorded more colony units than farmer practiced sugar syrup. At the end of six months storage period, both Rhizobium and Phosphorus Solubilizing Bacteria with biofriendly polymer recorded sufficient number of colony units on the surface of biologically coated pigeonpea seed. 
Fig.1 Effect of biofriendly polymer on the viability (CFU) of biofertilizers in the combined inoculations with bioprotectants $\left(\mathrm{CD}_{0.05}\right.$ is 3.793 and 3.117 for the combinations of Rhizobium and Phosphorus Solubilizing Bacteria, respectively)

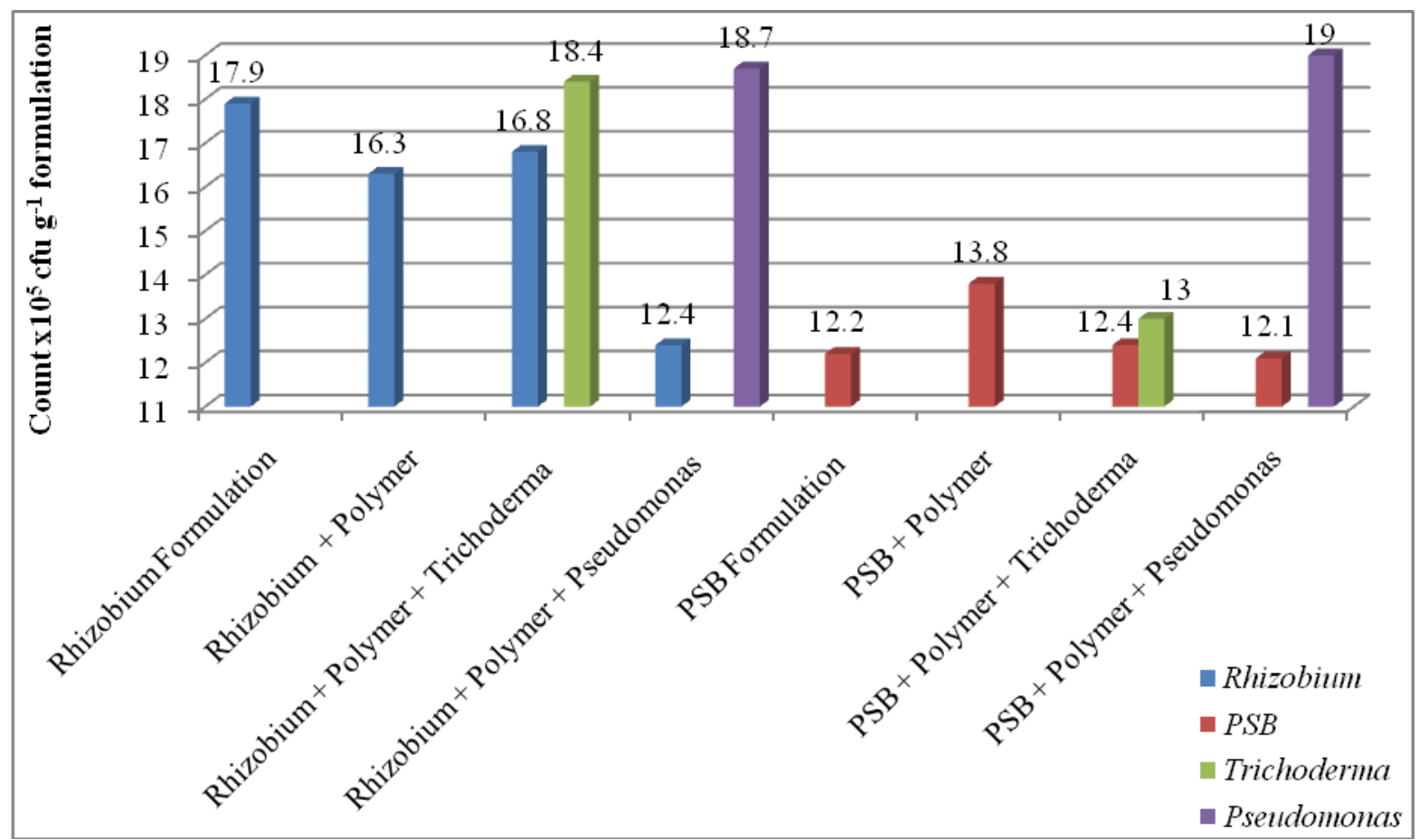

Fig.2 Viability and shelf life (CFU) of Rhizobium when coated on pigeon pea seed either along with Trichoderma or with Pseudomonas $\left(\mathrm{CD}_{0.05}\right.$ is 2.005 and 1.969 for the combinations of Rhizobium with Trichoderma and Pseudomonas, respectively)

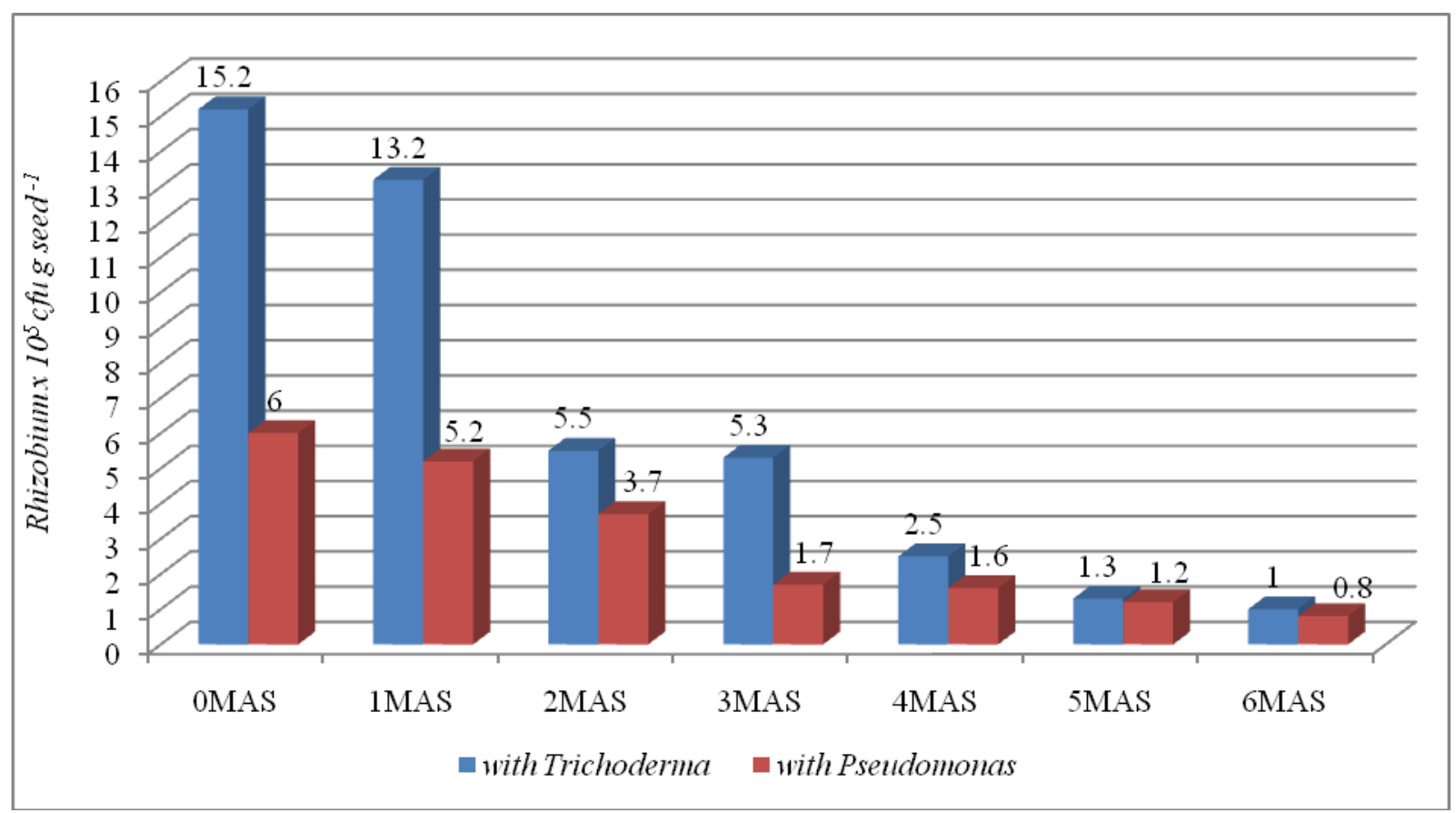


Fig.3 Viability and shelf life (CFU) of Phosphorous Solubilizing Bacteria (PSB) when coated on pigeon pea seed either along with Trichoderma or with Pseudomonas $\left(\mathrm{CD}_{0.05}\right.$ is 3.118 and 2.800 for the combinations of PSB with Trichoderma and Pseudomonas, respectively)

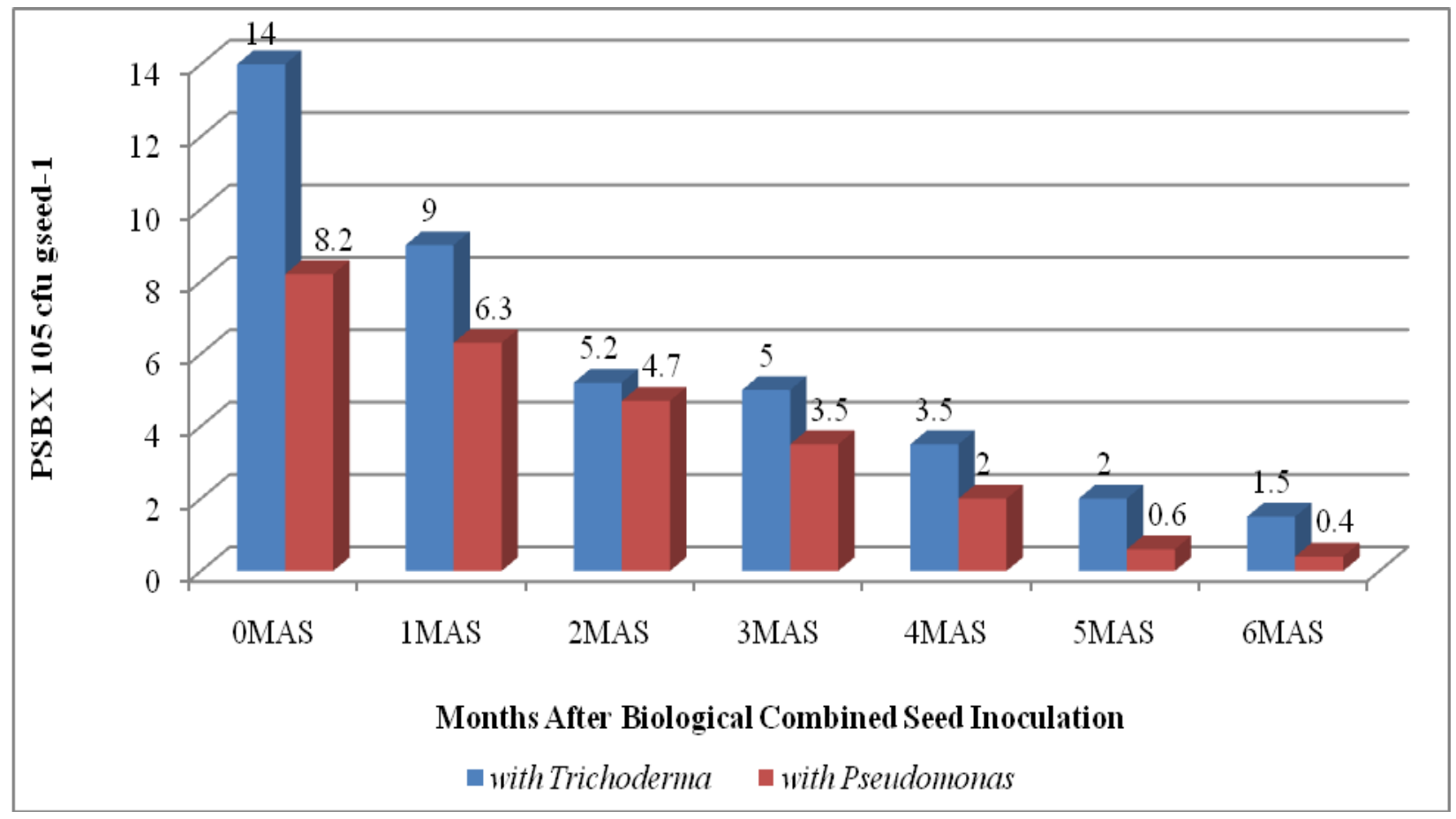

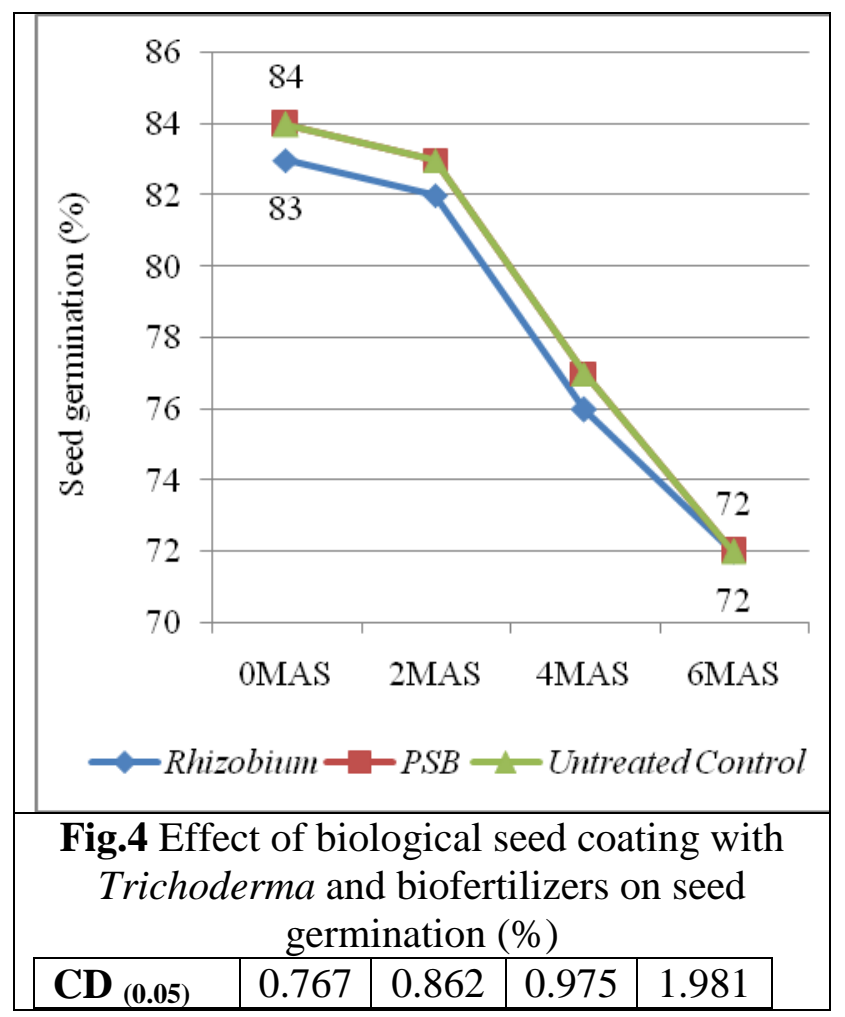

Note: MAS-Months After Storage

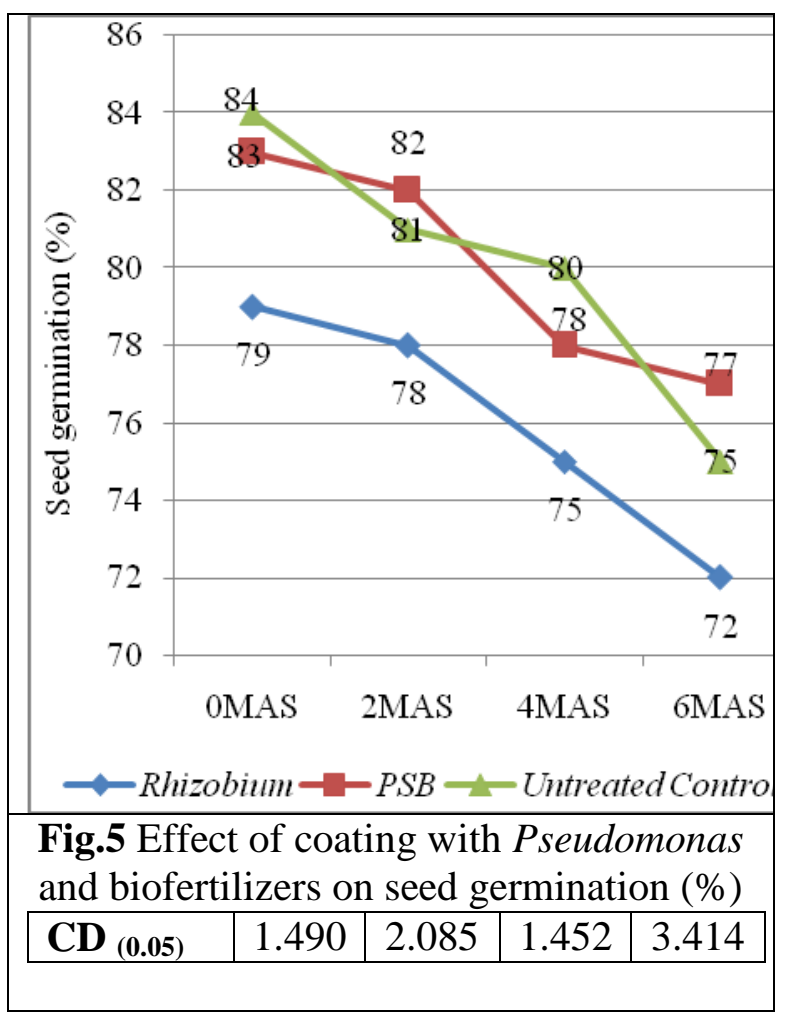




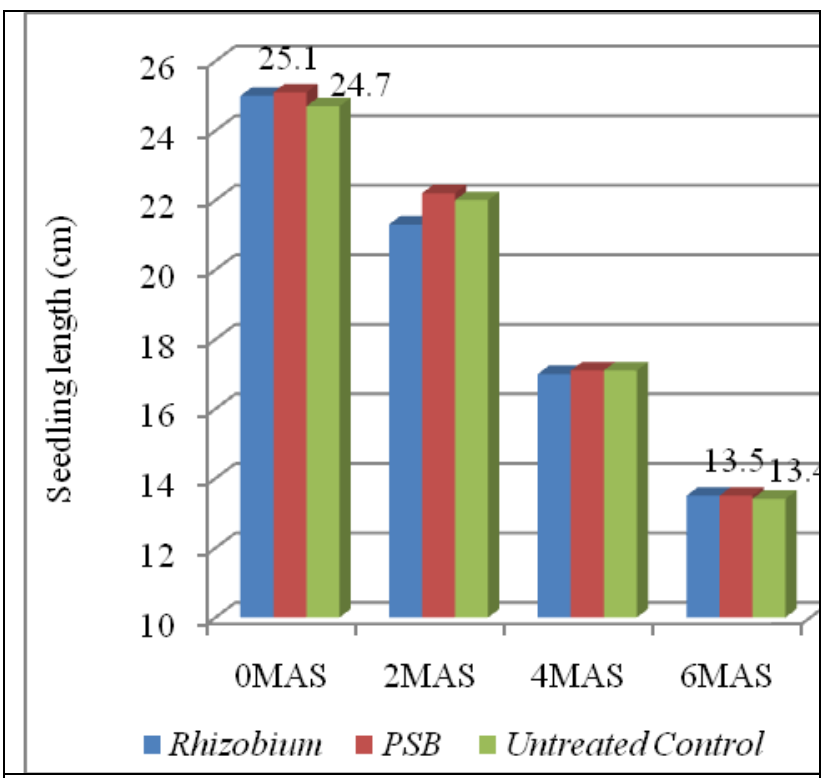

Fig.6 Effect of biological seed coating with Trichoderma and biofertilizers on seedling length $(\mathrm{cm})$

\begin{tabular}{|l|l|l|l|l|}
\hline $\mathbf{C D}_{(\mathbf{0 . 0 5})}$ & 2.514 & 1.560 & 2.055 & 1.015 \\
\hline
\end{tabular}

Note: MAS-Months After Storage

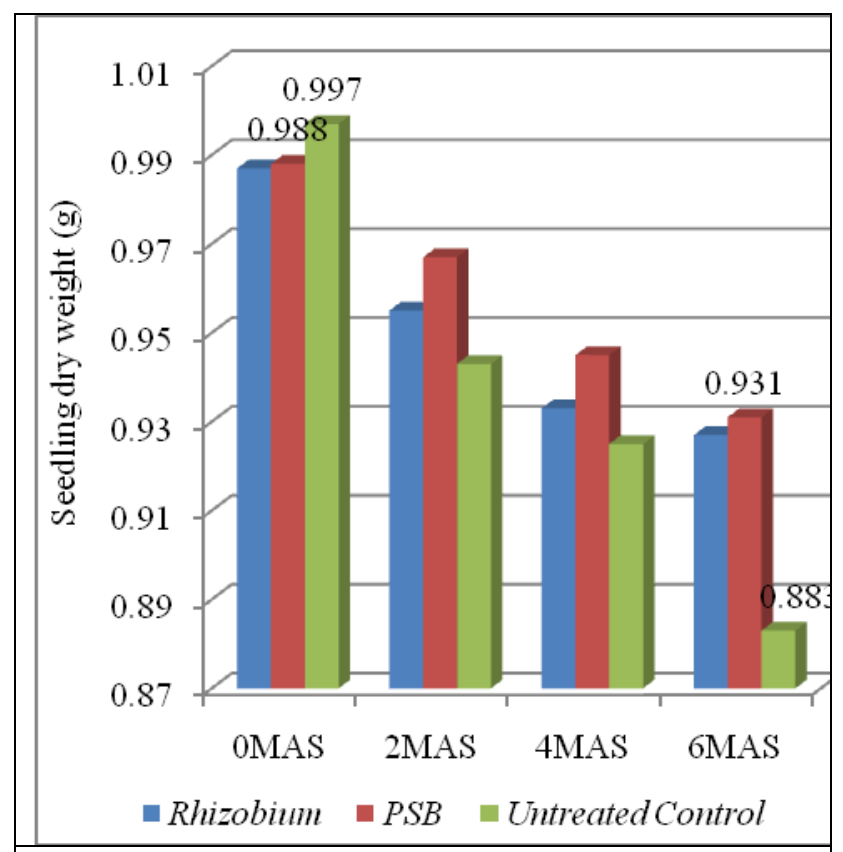

Fig.8 Effect of biological seed coating with Trichoderma and biofertilizers on seedling dry weight $(\mathrm{g})$

\begin{tabular}{|l|l|l|l|l|}
\hline CD $_{(\mathbf{0 . 0 5})}$ & 0.047 & N.S. & N.S. & 0.051 \\
\hline
\end{tabular}

Note: MAS-Months After Storage

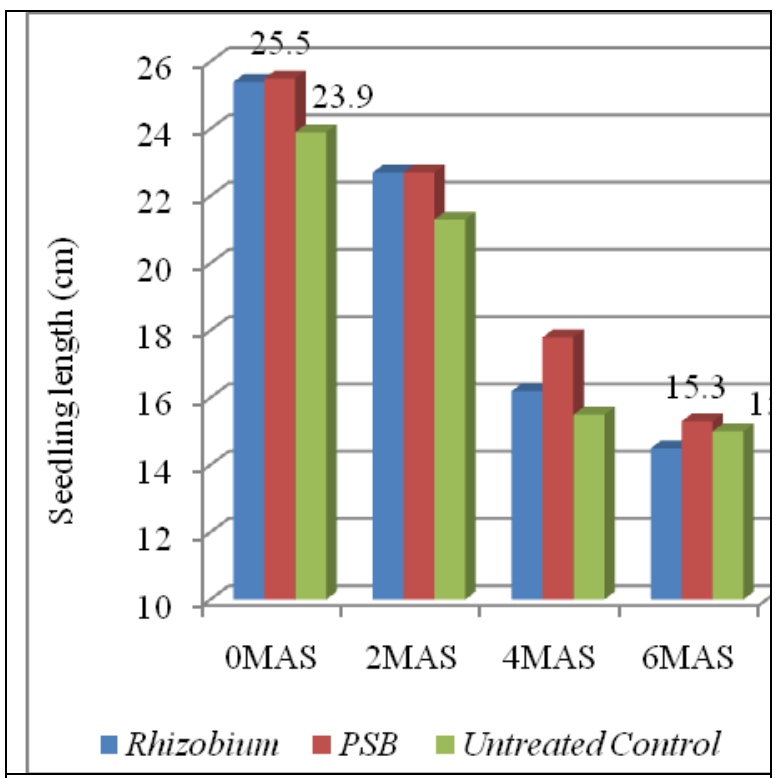

Fig.7 Effect of coating with Pseudomonas and biofertilizers on seedling length $(\mathrm{cm})$

\begin{tabular}{|l|l|l|l|l|}
\hline CD $_{(\mathbf{0 . 0 5})}$ & 1.721 & 2.144 & 1.685 & 0.704 \\
\hline
\end{tabular}

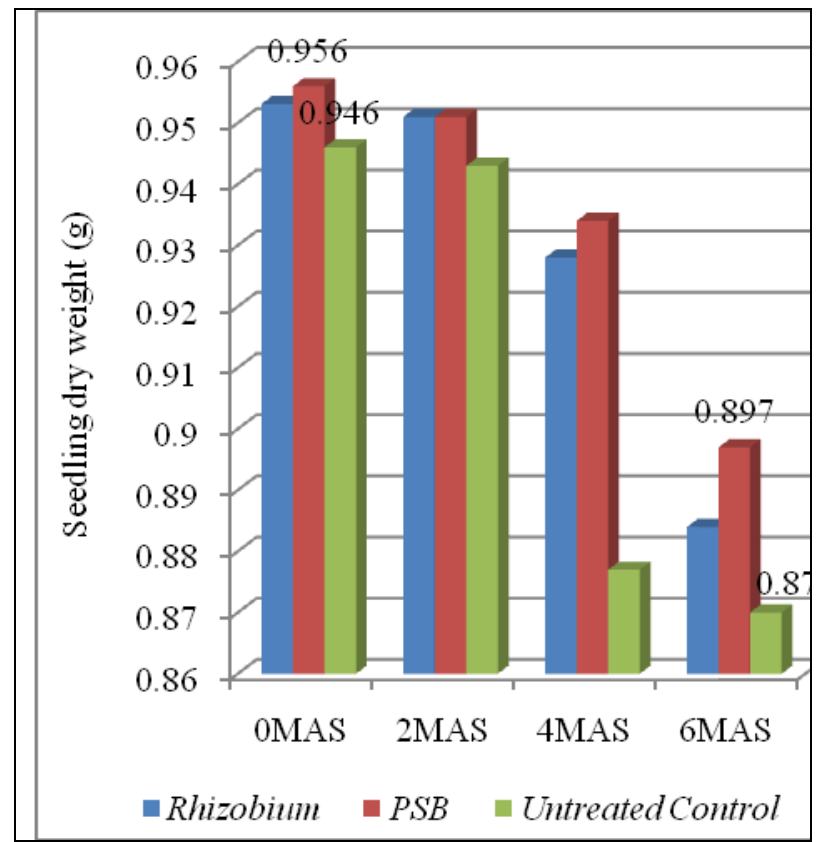

Fig.9 Effect of coating with Pseudomonas and biofertilizers on seedling dry weight $(\mathrm{g})$ \begin{tabular}{|l|l|l|l|l|}
\hline CD $_{(\mathbf{0 . 0 5})}$ & N.S & N.S. & N.S. & N.S. \\
\hline
\end{tabular} 


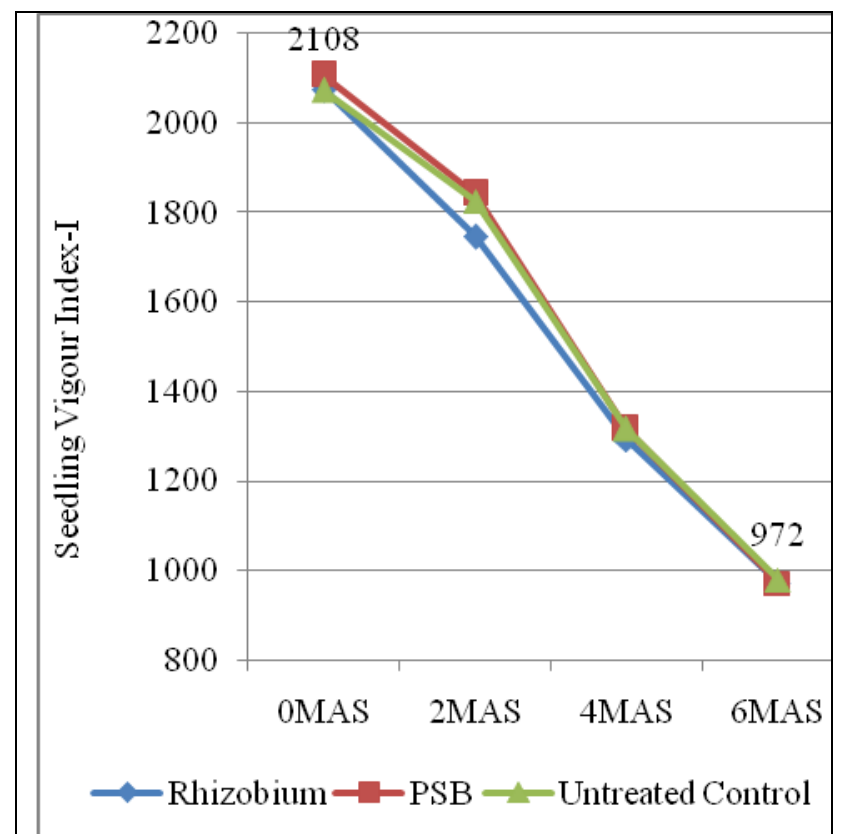

Fig.10 Effect of biological seed coating with Trichoderma and biofertilizers on SVI-1

\begin{tabular}{|l|c|c|c|c|}
\hline CD $_{(\mathbf{0 . 0 5})}$ & 210.1 & 124.4 & 123.53 & 93.8 \\
\hline
\end{tabular}

Note: MAS-Months After Storage

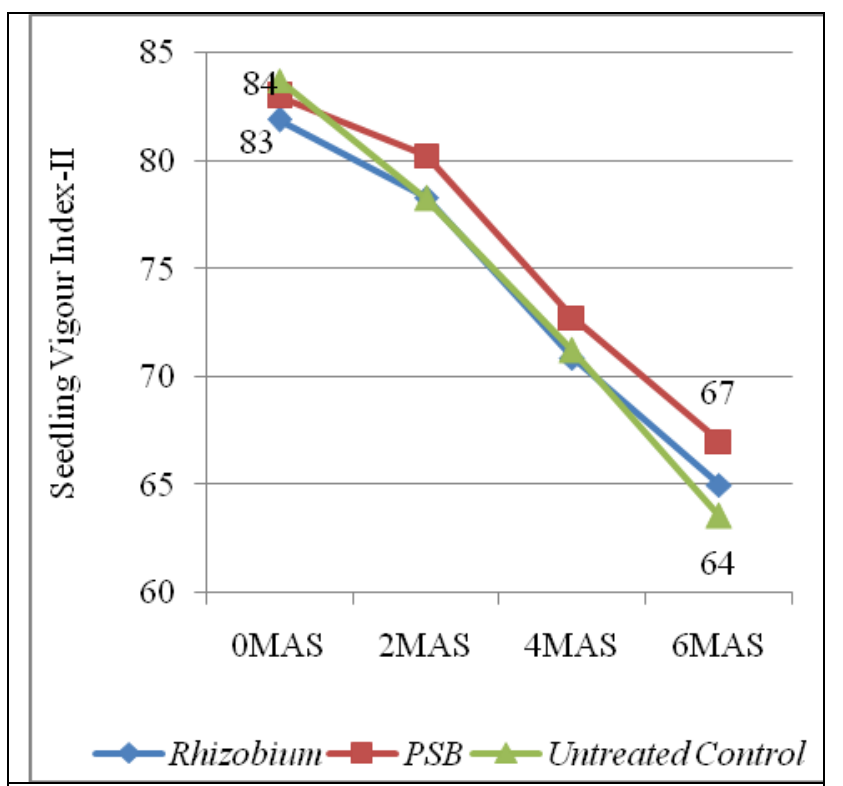

Fig.12 Effect of biological seed coating with Trichoderma and biofertilizers on SVI-2 \begin{tabular}{|l|l|l|l|l|}
\hline CD $_{(0.05)}$ & N.S. & N.S. & N.S. & 5.96 \\
\hline
\end{tabular}

Note: MAS-Months After Storage
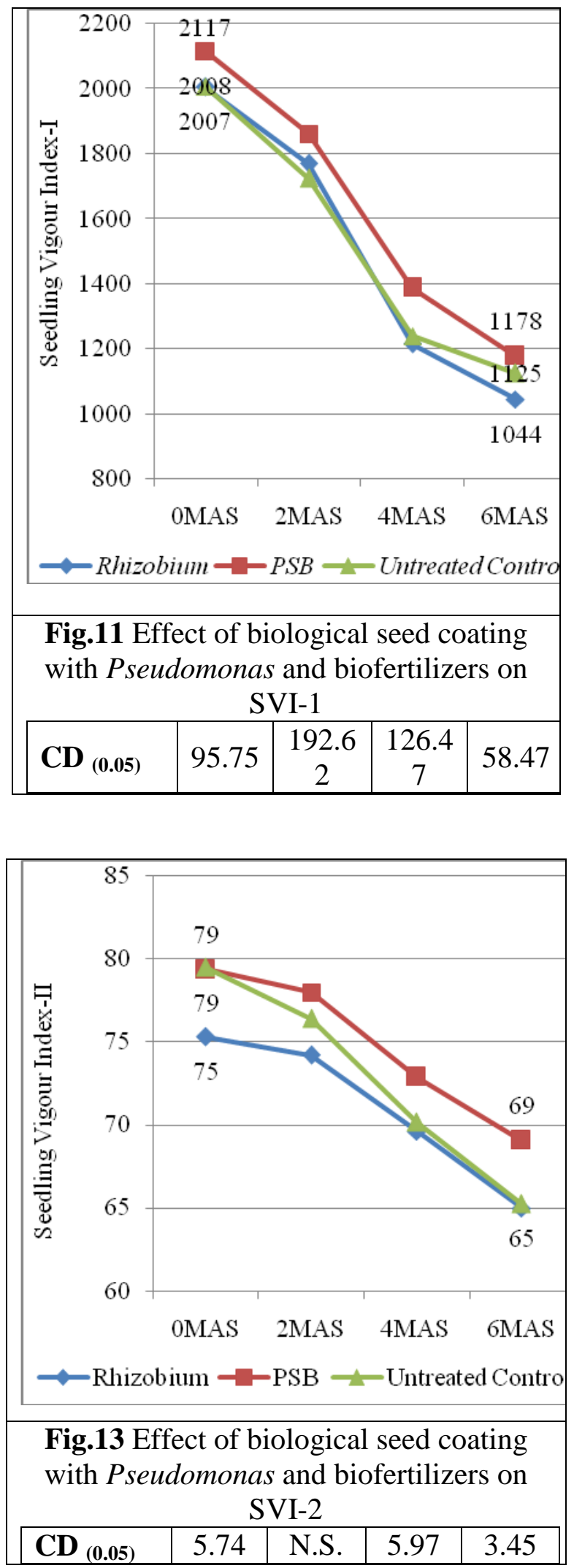


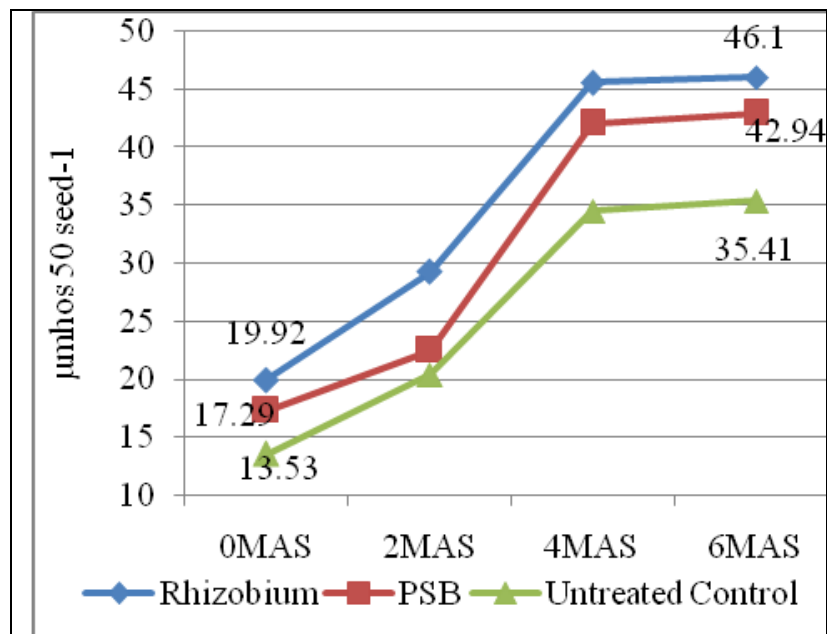

Fig.14 Effect of biological seed coating with Trichoderma and biofertilizers on EC

\begin{tabular}{|l|l|l|l|l|}
\hline $\mathbf{C D}_{(\mathbf{0 . 0 5})}$ & 1.671 & 2.387 & 2.298 & 1.550 \\
\hline
\end{tabular}

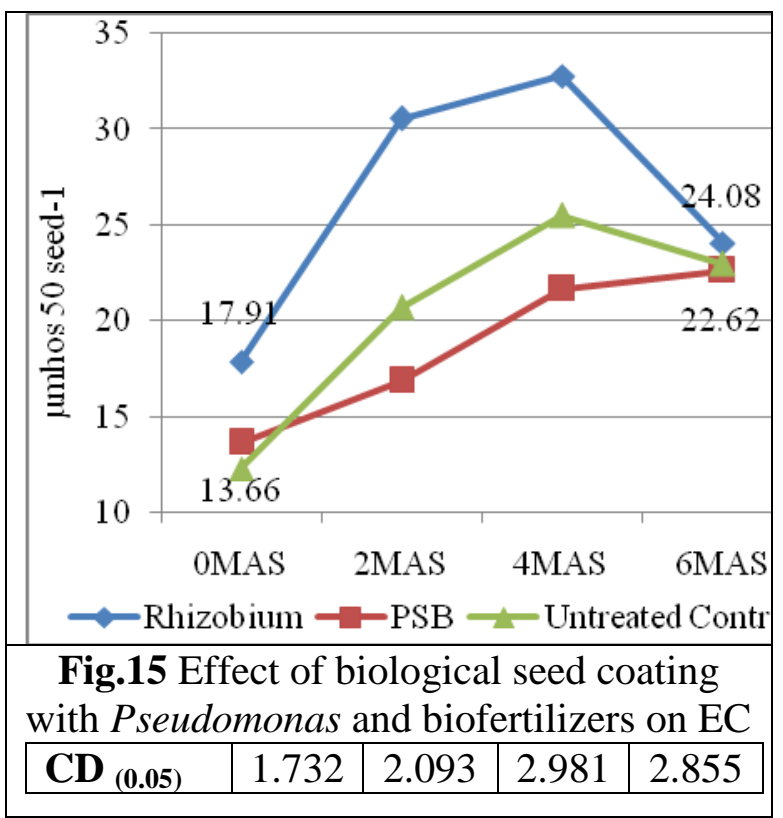

Note: MAS-Months After Storage

Plate.1 Effect of adjuvants on the shelf life (CFU) of Rhizobium and Phosphorus Solubilizing Bacteria on biologically coated seed of pigeonpea

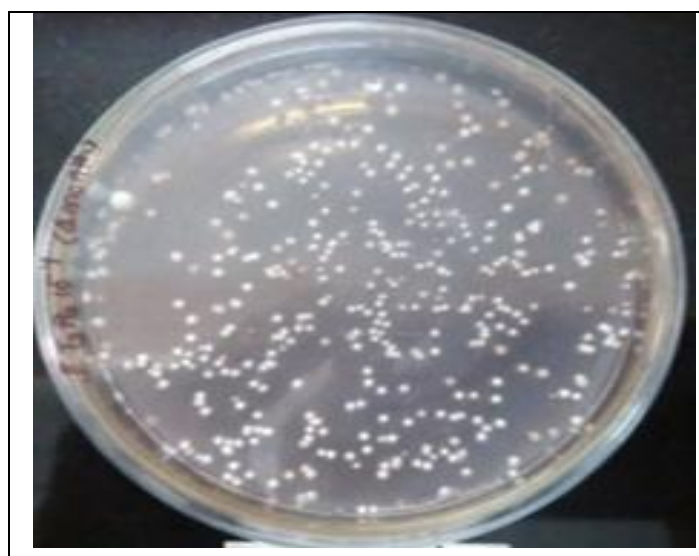

Rhizobium with polymer

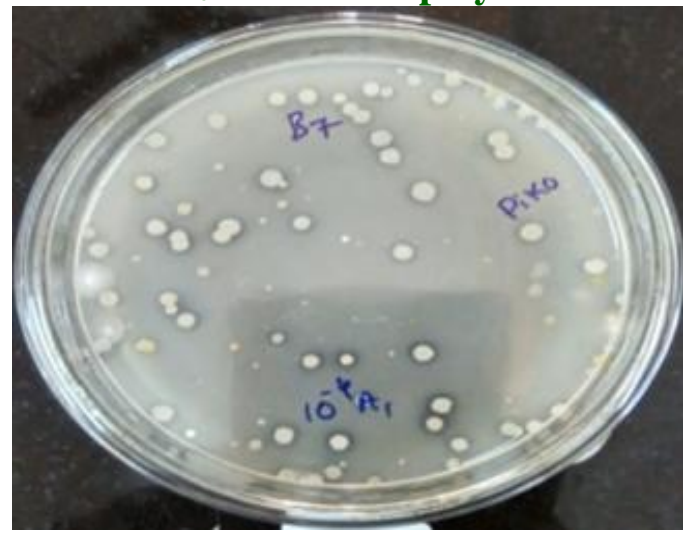

PSB with polymer

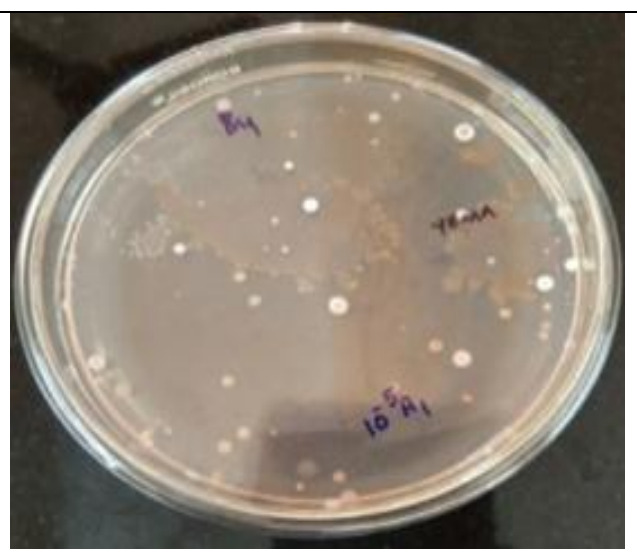

Rhizobium with sugar syrup

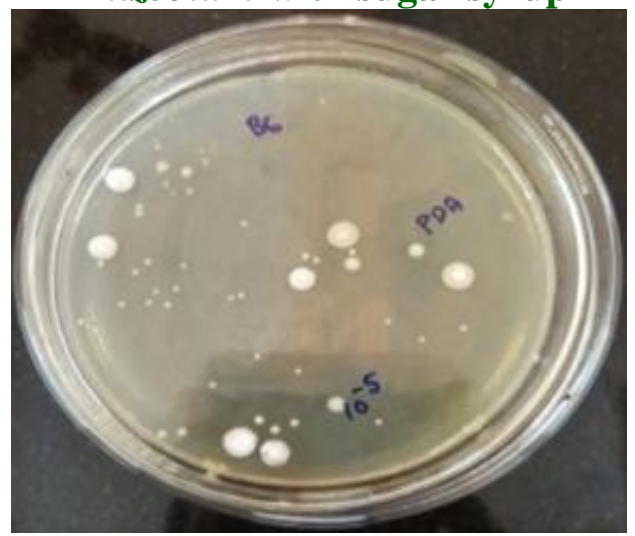

PSB with sugar syrup 
Table.1 Effect of bioprotectants and adjuvants on the shelf life of Rhizobium in combined inoculations either with Trichoderma or with Pseudomonas on biologically coated seed of pigeonpea

Treatment
$\begin{aligned} & \text { Seed + Rhizobium + Trichoderma } \\ & \text { viride+ Bio-friendly Polymer }\end{aligned}$
Seed + Rhizobium + Trichoderma
viride+ Sugar syrup
Seed + Rhizobium + Pseudomonas
fluorescens + Bio-friendly Polymer
Seed + Rhizobium + Pseudomonas
fluorescens + Sugar syrup
Mean
C.D.

\begin{tabular}{|c|c|c|c|c|c|c|}
\hline \multicolumn{7}{|c|}{ Rhizobium $\times 10^{5}$ cfu g seed $^{-1}$} \\
\hline 15.2 & 13.2 & 6.4 & 5.3 & 2.5 & 1.3 & 1.0 \\
\hline 12.7 & 7.2 & 5.5 & 3.6 & 1.7 & 1.1 & 0.9 \\
\hline 6.0 & 5.2 & 3.7 & 1.7 & 1.6 & 1.2 & 0.8 \\
\hline 5.2 & 4.4 & 2.2 & 1.3 & 1.5 & 1.1 & 0.8 \\
\hline $\mathbf{9 . 7 7}$ & $\mathbf{7 . 5}$ & $\mathbf{4 . 4 5}$ & $\mathbf{2 . 9 7}$ & $\mathbf{1 . 8 2}$ & $\mathbf{1 . 1 7}$ & $\mathbf{0 . 8 7}$ \\
\hline 2.829 & 3.519 & 2.367 & 2.163 & NS & NS & NS \\
\hline
\end{tabular}

Note: MAS: Months After Storage

Table.2 Effect of bioprotectants and adjuvants on the shelf life of Phosphorous Solubilizing Bacteria (PSB) in combined inoculations either with Trichoderma or with Pseudomonas on biologically coated seed of pigeonpea

\begin{tabular}{|c|}
\hline Treatment \\
\hline $\begin{array}{l}\text { Seed + PSB + Trichoderma viride+ Bio- } \\
\text { friendly Polymer }\end{array}$ \\
\hline $\begin{array}{l}\text { Seed }+P S B+\text { Trichoderma viride+ } \\
\text { Sugar syrup }\end{array}$ \\
\hline $\begin{array}{l}\text { Seed + PSB + Pseudomonas fluorescens } \\
\text { + Bio-friendly Polymer }\end{array}$ \\
\hline $\begin{array}{l}\text { Seed + PSB + Pseudomonas fluorescens } \\
+ \text { Sugar syrup }\end{array}$ \\
\hline Mean \\
\hline C.D. \\
\hline
\end{tabular}

Note: MAS: Months After Storage

The biofriendly polymer might have retained and supplied sufficient nutrients required for cell multiplication even after six months of inoculation rather than sugar syrup. Similarly, Chennakeshavulu et al., (2013) also reported the mass multiplication and shelf life of Pseudomonas fluorescens in farm yard manure which has supported maximum growth followed by gobar gas slurry.
Phosphorous Solubilizaing Bacteria $x 10^{5} \mathrm{cfu}_{\mathrm{g}} \mathrm{seed}^{-1}$

\begin{tabular}{|c|c|c|c|c|c|c|}
\hline OMAS & 1MAS & 2MAS & 3MAS & 4MAS & 5MAS & 6MAS \\
\hline 14.0 & 9.0 & 5.0 & 5.2 & 3.5 & 2.0 & 1.5 \\
\hline 5.2 & 4.8 & 3.9 & 2.5 & 2.0 & 1.3 & 0.7 \\
\hline 8.2 & 6.3 & 4.7 & 3.5 & 2.0 & 0.6 & 0.4 \\
\hline 5.3 & 4.6 & 3.7 & 1.8 & 1.1 & 0.5 & 0.3 \\
\hline $\mathbf{8 . 1 8}$ & $\mathbf{6 . 1 8}$ & $\mathbf{4 . 3 3}$ & $\mathbf{3 . 2 5}$ & $\mathbf{2 . 1 5}$ & $\mathbf{1 . 1}$ & $\mathbf{0 . 7 3}$ \\
\hline 3.312 & 3.053 & NS & NS & NS & 1.07 & 0.571 \\
\hline
\end{tabular}

In the combined inoculations, Rhizobium with Trichoderma showed high colony counts than with Pseudomonas. Similarly, Phosphorus Solubilizing Bacteria also showed high colony counts in its combined inoculation with Trichoderma than with Pseudomonas and the same trend was continued throughout the storage period of six months. The same trend was continued throughout the storage 
period of six months. This might be due to the compatibility and antagonistic reactions among the biological agents. In the same line O'callaghan et al., (2006) was formulated and applied Pseudomonas fluorescens strain F113 to onion seed using patented biofriendly polymer technology developed at Agricultural Research, Lincoln, New Zealand. They reported that the initial loadings on seeds ranged between $8.6 \times 10^{6}-1.1 \times 10^{7}$ bacteria seed $^{-1}$. In a preliminary screening of four different formulations, shelf life studies indicated that most formulations maintained high cell numbers on seed stored at $4^{0} \mathrm{C}$ for up to 70 days. Bacterial numbers declined on seed stored at $20^{\circ} \mathrm{C}$, but significant numbers of bacteria remained viable after 70 days storage.

Fifty percent reduction in Rhizobium colony count was observed after 2 months of seed coating and thereafter a gradual reduction in the colony count was observed upto six months. With the advancement of storage period there was a gradual loss in the viability of biofertilize might be due to reduction in the availability of sufficient nutrients for cell multiplication.

Similarly, Harish et al., (2008); Verma et al., (2010) and Singh et al., (2013) reported that the Pseudomonas multiplication rate might have been restricted due to competition for food and space by other organisms in the consortia.

Effect of biological seed coating with combined inoculation of biofertilizers and biocontrol agents on pigeonpea seed germination (\%) and germination parameters

With the advancement of storage period there was a gradual decrease in the seed germination. Six months after storage, more seed germination was recorded in the seeds that are co-inoculated with biofertilizers and Pseudomonas than with Trichoderma. These results revealed that polymer coating reduced the rate of seed deterioration and enhanced seed storability by enhancing seed germination even with biological agents.

Yadav et al., 2013 also observed that the combined application of the microbes enhanced seed germination and plant growth better than their individual application. Among the combinations all combinations comprising of 'Trichoderma' showed better results compared to the others and the triple microbial combination demonstrated best results in terms of seed germination and seedling growth in both chickpea and rajma.

These findings are in conformity with the findings of Zhang $\mathrm{Li}$ (2002) in wheat and corn, Wilson and Geneve (2004) in corn, Suma and Srimathi (2004) in sesame, Giang and Gowda, (2007) in hybrid rice, Kumar et al., (2007) in soybean, Basavaraj et al., (2008) in onion, Manjunatha et al., (2008) in chilli, Shakuntala et al., (2010) in sunflower, Vinodkumar et al., (2013) in pigeon pea, Verma and Verma (2014) in soybean, Kaushik et al., (2014) in maize, Ambika et al., (2014) in hybrid rice, Shakuntala et al., (2014) in sunflower, who have reported an increase in seed germination in the polymer coated seeds compared to uncoated seeds by reducing the number of abnormal seedlings.

Among the biofertilizers, comparatively Phosphorus Solubilizing Bacteria recorded good seedling length $(\mathrm{cm})$ and seedling dry weight $(\mathrm{mg})$ throughout the storage period of six months than Rhizobium. This might be due to the fact that polymer material might have supplied more growth promoters and nutrients and increased seedling length. These findings are in line with the Vinod Kumar et al., (2013) in pigeon pea by reporting enhanced seedling length in polymer coated 
seeds. Chennakesavulu et al., (2013) reported that the soil application with Pseudomonas + soil drenching with fungicide was superior in reducing per cent disease incidence and increasing plant growth parameters like root length, shoot length, dry weight of shoot and root

Effect of biological seed coating with combined inoculation of biofertilizers and biocontrol agents on pigeonpea seedling vigour

With the advancement of storage period there was a gradual decrease in the seedling vigour. Six months after storage, significantly high seedling vigour index-I and II was observed with the combined inoculation of PSB with Pseudomonas than with Trichoderma. These results revealed that polymer coating reduced the rate of seed deterioration and enhanced seed storability by enhancing seed vigour even with biological agents. These findings are in conformity with the findings of Yadav et al., (2010) in chick pea, Singh et al., (2013) in Trigonella foenumgraecum and Devi (2004) in sorghum who have reported an increase in seed germination and seedling vigour in the polymer coated seeds compared to uncoated seeds.

Irrespective of treatments, there was an increase in the electrical conductivity throughout the storage period of six months. Among the biofertilizers, seeds coated with Rhizobium showed more electrical conductivity than PSB and untreated control.

\section{Acknowledgements}

The authors gratefully acknowledge the financial help rendered by the Professor Jayashankar Telangana State Agricultural University, Hyderabad and technical support rendered by the staff of the Department of Seed Science \& Technology and Department of Agriculture Microbiology and Bio-energy, College of Agriculture, Rajendranagar, PJTSAU, Rajendranagar, Hyderabad (India) and Centor India, Hyderabad.

\section{References}

Chennakesavulu, M., Reddikumar, M. \& Eswarareddy, N.P. (2013). Mass multiplication and shelf life studies of Pseudomonas fluorescens against pigeon pea wilt. Indian Journal of Plant Protection. 41(1): 45-49.

Food and Agriculture Organization (2016)

Giang, P.L. \& Gowda, R. (2007). Influence of seed coating with synthetic polymers and chemicals on seed quality and storability of hybrid rice (Oryza sativa L.). Omonrice. 68-74.

Harish, S., Kavino, M., Kumar, N., Saravanakumar, D., Soorianathasundaram, K. \& Samiyappan, R. (2008). Bio hardening with plant growth promoting rhizosphere and endophytic bacteria induces systemic resistance against banana bunchy top virus. Applied Soil Ecology. 39:187-200.

India stat (2013)

Indian Institute of Pulse Research (2014)

International Seed Testing Association (2009)

Kumar, J., Nisar, K.., Kumar, M.B.A., Walia, S., Shakil, N.A., Prasad, R. \& Parmar, B.S. (2007). Development of polymeric seed coats for seed quality enhancement of soybean (Glycine max L.). Indian Journal of Agricultural Sciences. 77 (11): 738743.

O'callaghan, M., Swaminathan, J., Lottmann, J., Wright, D.A. \& Jackson, T.A. (2006). Seed coating with biocontrol strain Pseudomonas fluorescens F113. New Zealand Plant Protection. 59:80-85 Panse, V.G. \& Sukhatme, P.V. (1985). Statistical methods for agricultural 
workers $2^{\text {nd }}$ edn. pp/381, I.C.A.R., New Delhi.

Shakuntala, N.M., Vyakaranahal, B.S., Shankergoud, I., Deshpande, V.K., Pujari, B.T. \& Nadaf, H.L. (2010). Effect of seed polymer coating on growth and yield of sunflower hybrid RSFH-130. Karnataka journal of Agricultural Sciences. 23 (5): 708-11.

Singh, R., Arora, N.K., Preeti, G \& Shattarohan, L. (2013). Enhancement of plant growth of Trigonella foenumgraecum by coinoculation of fluorescent Pseudomonas and Rhizobium for the sustainability of agriculture. Asian Journal of Plant Science and Research. 3 (3):74-79.

Suma, N. and Srimathi, P. (2014). Influence of polymer coating on seed and seedling quality characteristics. IOSR Journal of Agriculture and Veterinary Science. 7 (5): 48-50.

Verma, J.P., Yadav, J. \& Tiwari, K.N. (2010). Application of Rhizobium spp. (BHURC01) and Plant Growth Promoting Rhizobacteria on nodulation, plant bio mass and yield of Chick pea (Cicer arietenum.L). International Journal of Agricultural Research. 5 (3): $148-156$.
Vinod Kumar, S.B., Vyakaranahal, B.S., Dhananjaya, P., Hipparagi, Y. \& Asha, A.M. (2013). Effect of seed polymer coating on field performance and quality of pigeon pea (Cajanus cajan L.). Environment and Ecology. 31(1): 43-46.

Wilson, T.T. \& Geneve, R.L. (2004). The impact of film coating on initial water uptake and imbibitional chilling injury and low vigour sh2 sweet corn seeds. Seed Science and Technology. 32(2): 271-281.

Yadav, Sudheer Kumar, Dave Anushree, Sarkar Ankita, Singh Harikesh Bahadur \& Sarma Birinchi Kumar. (2013). Co-inoculated biopriming with 'Trichoderma', 'Pseudomonas' and 'Rhizobium' improves crop growth in 'Cicer arietinum' and 'Phaseolus vulgaris'. International Journal of Agriculture, Environment \& Biotechnology. 6(2): $255-259$

Zhang, Li. (2002). Effects of water holding polymer agent on germination and vigour of wheat and corn seeds. Journal of Anhui Agricultural Sciences. 6:6874.

\section{How to cite this article:}

Jagadeesh V., P. Sujatha, S. Triveni, K. Keshavulu and Raghavendra K. 2018. Pigeonpea Biological Seed Coating: Combined Inoculation of Biofertilizers and Bioprotectants. Int.J.Curr.Microbiol.App.Sci. 7(06): 3692-3707. doi: https://doi.org/10.20546/ijcmas.2018.706.433 